\title{
THE MORPHOLOGICAL CHARACTERISTICS OF THE ASSOCIATION FOOTBALL PLAYER
}

\author{
W. BELL \& G. RHODES \\ Department of Physical Education, College of Education, Cardiff, Wales.
}

\section{Introduction}

Association football is a game played by an extremely large number of participants at varying levels of competence and in many countries throughout the world. But in spite of this wide appeal there appear to be surprisingly few studies which have dealt specifically with the morphological characteristics of the association football player. Size is often an important consideration in player performance, and usually the higher the level of performance the more critical its role. The manifestation of size is more particular in those games where there is a high degree of player specialisation. Shape too, although a rather more subtle concept in terms of player position can often contribute a great deal and can sometimes can provide distinct physical advantages for specific playing positions. Rugby union football is a good example where both these factors operate (Bell, 1973a, 1973b).

The morphological dimensions of players in association football is limited by and large to height and weight. Hirata (1966) has reported these data for competitors taking part in the Tokyo Olympic Games and similar information has been provided for players of various levels of ability in Zagreb (Medved, 1966). As well as height and weight, physique has been described for a group of prominent Czechoslovakian players by Chovanova and Zrubak (1972). A recent summary of the physique of athletic groups has been given by Carter (1970).

However, all these studies dealing with the association football player have tended to pool players from all the playing positions. What has not so far been considered are differences between the various playing positions themselves. The present study, therefore, sets out to describe and analyse some of the more obvious morphological dimensions of a group of soccer players according to their playing position.

\section{Method}

Subjects were drawn from a college student population who over the years had made up the 'pool' of first team players. During this period the team had been consistently successful at both regional and national levels. The distinction between amateur and professional has now disappeared but at the time of competition a small number of players turned out for professional clubs when free to do so and a few had gained Welsh Amateur National status.
It is preferable, wherever possible, to study players according to their functional commitment rather than collectively as a group. Assembling players without reference to playing position may well mask differences between them that are not obviously apparent. For this reason each player was classified according to his preferred playing position. For the present purposes players were assigned to one of the following groups: goalkeepers, defenders, midfield players and strikers. The total size of the sample was 61 ; of these 7 were goalkeepers, 20 defenders, 18 midfield players, and 16 strikers. The mean decimal age of the group was 20.8 years.

Using the full range of Harpenden equipment a series of $\mathbf{2 0}$ anthropometric measurements were taken on each subject. The techniques employed were those recommended by Weiner and Lourie (1969) and Tanner (1964).

Nine measures of size were recorded. These included total body mass, stature, sitting height, biacromial and bi-iliac diameters, and bicondylar diameters of the humerus and femur. Subischial length was determined by the subtraction of sitting height from stature. Subcutaneous tissue measurements were taken on the lefthand side of the body at the biceps, triceps, subscapular, suprailiac, medial calf and mid-thigh sites. Two circumferences were taken at the upper-arm and one each at the gluteal fold, mid-thigh and maximal calf sites. These were also taken on the left-hand side of the body.

Since two observers had been involved in collecting the data 'between-observer' as well as the usual 'withinobserver' errors of measurement were determined. These values compared quite favourably with others in the literature. Physique was assessed using the anthropometric method of Heath and Carter (1967). Betweenobserver reliability was determined on a sub-sample using mean differences in ratings between observers for each of the three components. In component order these values were $+0.1,+0.05$ and -0.05 . Although body composition was not considered in any great detail we thought it might be useful to provide some preliminary estimates of tissue composition. These were made using the procedures of Durnin and Rahaman (1967). Total body fat (TBF) was determined from calculated density, and the lean body mass (LBM) from the subtraction of TBF from total body mass. 
Results

Mean values and standard deviations for some of the measurements of body size are set out in Table I. To test for differences between the various playing positions a one-way analysis of variance was applied to each of the measured and derived variables. Variance ratios ranged from 1.96 to $\mathbf{5 . 9 9}$ for body size but none were found to be significant $(p>0.05)$. The results for limb circumferences and subcutaneous tissue are given in Table II. For these dimensions the values of $F$ ranged from 0.42 to 5.30 and all were found to be non-significant $(p>$ 0.05 ). Where a general comparison between playing positions gave a result which was not significant we did not consider it worthwhile to proceed further with an analysis between particular playing positions.

\section{Table I}

Mean values and standard deviations for the dimensions of body size for each of the playing units

$\begin{array}{lcccc} & \begin{array}{l}\text { Goalkeeper } \\ (\mathrm{n}=7)\end{array} & \begin{array}{l}\text { Defender } \\ (\mathrm{n}=20)\end{array} & \begin{array}{c}\text { Midfield } \\ (\mathrm{n}=18)\end{array} & \begin{array}{c}\text { Striker } \\ (\mathrm{n}=16)\end{array} \\ \text { Body mass } & 80.80 & 72.51 & 68.05 & 69.19 \\ \text { (kg) } & \pm 9.07 & \pm 6.44 & \pm 7.00 & \pm 7.33 \\ \text { Stature } & 180.3 & 176.8 & 173.4 & 177.2 \\ \text { (cm) } & \pm 5.3 & \pm 4.9 & \pm 5.2 & \pm 5.0 \\ \text { Sitting height } & 97.3 & 94.5 & 93.1 & 94.0 \\ \text { (cm) } & \pm 2.3 & \pm 3.1 & \pm 2.5 & \pm 2.4 \\ \text { Subischial } & 83.0 & 82.8 & 80.3 & 83.1 \\ \text { (cm) } & \pm 3.4 & \pm 5.1 & \pm 3.5 & \pm 3.8 \\ \text { Humerus } & 7.0 & 7.0 & 6.9 & 6.8 \\ \text { (cm) } & \pm 0.3 & \pm 0.2 & \pm 0.4 & \pm 0.3 \\ \text { Femur } & 10.1 & 10.0 & 9.5 & 9.7 \\ \text { (cm) } & \pm 0.4 & \pm 0.4 & \pm 0.4 & \pm 0.4 \\ \text { Biacromial } & 42.5 & 41.2 & 39.8 & 40.1 \\ \text { (cm) } & \pm 2.0 & \pm 1.7 & \pm 1.5 & \pm 2.4 \\ \text { Bi-iliac } & 29.8 & 28.2 & 27.6 & 28.2 \\ \text { (cm) } & \pm 1.0 & \pm 1.6 & \pm 2.3 & \pm 1.7\end{array}$

From the results in Table III our sample shows that the goalkeepers had slightly lower density values and consequently a higher fat content than any of the outfield groups. The outfield players differed little in percentage fat values where the range was only from 14.64 to 14.74. Absolute weight of body fat was greater in goalkeepers by about $3 \mathrm{~kg}$; they also had larger amounts of LBM by roughly $5-9 \mathrm{~kg}$ compared with other groups. Despite noticeable differences between goalkeepers and other groups no significant differences were apparent between any of the playing positions. Variance ratios ranged in value from 1.27 to $6.19(p>0.05)$.
Table II

Mean values and standard deviations for four limb circumferences and four body skinfolds for each of the playing units

$\begin{array}{lrrrr} & \begin{array}{l}\text { Goalkeeper } \\ (\mathrm{n}=7)\end{array} & \begin{array}{l}\text { Defender } \\ (\mathrm{n}=20)\end{array} & \begin{array}{c}\text { Midfield } \\ (\mathrm{n}=18)\end{array} & \begin{array}{l}\text { Striker } \\ (\mathrm{n}=16)\end{array} \\ \text { Upper-arm } & 30.4 & 28.6 & 27.2 & 28.0 \\ \text { (cm) } & \pm 2.1 & \pm 1.9 & \pm 1.8 & \pm 2.0 \\ \text { Gluteal thigh } & 58.5 & 56.6 & 54.7 & 55.3 \\ \text { (cm) } & \pm 3.9 & \pm 2.5 & \pm 3.3 & \pm 3.1 \\ \text { Mid-thigh } & 54.7 & 52.4 & 50.3 & 50.9 \\ \text { (cm) } & \pm 2.9 & \pm 2.7 & \pm 2.9 & \pm 2.5 \\ \text { Calf } & 38.5 & 37.5 & 36.0 & 36.5 \\ \text { (cm) } & \pm 2.0 & \pm 2.2 & \pm 2.0 & \pm 1.8 \\ \text { Sub biceps } & 5.4 & 4.5 & 4.1 & 4.3 \\ \text { (mm) } & \pm 0.2 & \pm 0.1 & \pm 0.1 & \pm 0.1 \\ \text { Sub triceps } & 9.7 & 9.1 & 8.5 & 8.8 \\ \text { (mm) } & \pm 0.3 & \pm 0.3 & \pm 0.2 & \pm 0.3 \\ \text { Sub subscapular } & 11.6 & 8.9 & 8.9 & 8.9 \\ \text { (mm) } & \pm 0.5 & \pm 0.2 & \pm 0.2 & \pm 0.2 \\ \text { Sub suprailiac } & 14.6 & 11.0 & 11.9 & 11.6 \\ \text { (mm) } & \pm 0.7 & \pm 0.3 & \pm 0.4 & \pm 0.3\end{array}$

\section{Table III}

Mean values and standard deviations for total body fat (TBF) and lean body mass (LBM) according to playing unit

$\begin{array}{lllll} & \begin{array}{l}\text { Goalkeeper } \\ (\mathrm{n}=7)\end{array} & \begin{array}{l}\text { Defender } \\ (\mathrm{n}=20)\end{array} & \begin{array}{l}\text { Midfield } \\ (\mathrm{n}=18)\end{array} & \begin{array}{l}\text { Striker } \\ (\mathrm{n}=16)\end{array} \\ \text { TBF } & 16.94 & 14.74 & 14.64 & 14.66 \\ (\%) & \pm 4.02 & \pm 2.53 & \pm 2.82 & \pm 2.73 \\ \text { LBM } & 83.06 & 85.26 & 85.36 & 85.34 \\ (\%) & \pm 4.02 & \pm 2.53 & \pm 2.82 & \pm 2.73 \\ \text { TBF } & 13.85 & 10.72 & 10.09 & 10.20 \\ (\mathrm{~kg}) & \pm 4.30 & \pm 2.22 & \pm 2.66 & \pm 2.52 \\ \text { LBM } & 66.95 & 61.79 & 57.96 & 58.99 \\ (\mathrm{~kg}) & \pm 6.22 & \pm 5.46 & \pm 4.97 & \pm 5.93\end{array}$

Exactly the same procedure was applied to the components of the somatotype data. None of the $F$ ratios (0.79 to 6.00) between the playing groups in endomorphy, mesomorphy or ectomorphy were significant ( $p$ $>0.05)$. The results can be seen in Table IV. For a further look at the data somatotypes were classified according to primary and secondary components and were finally placed into seven categories. Where numbers permitted a chi-square test was carried out on all possible combinations of playing groups to find whether there were any differences in the way in which players were distributed between groups. Thus goalkeepers were contrasted with 


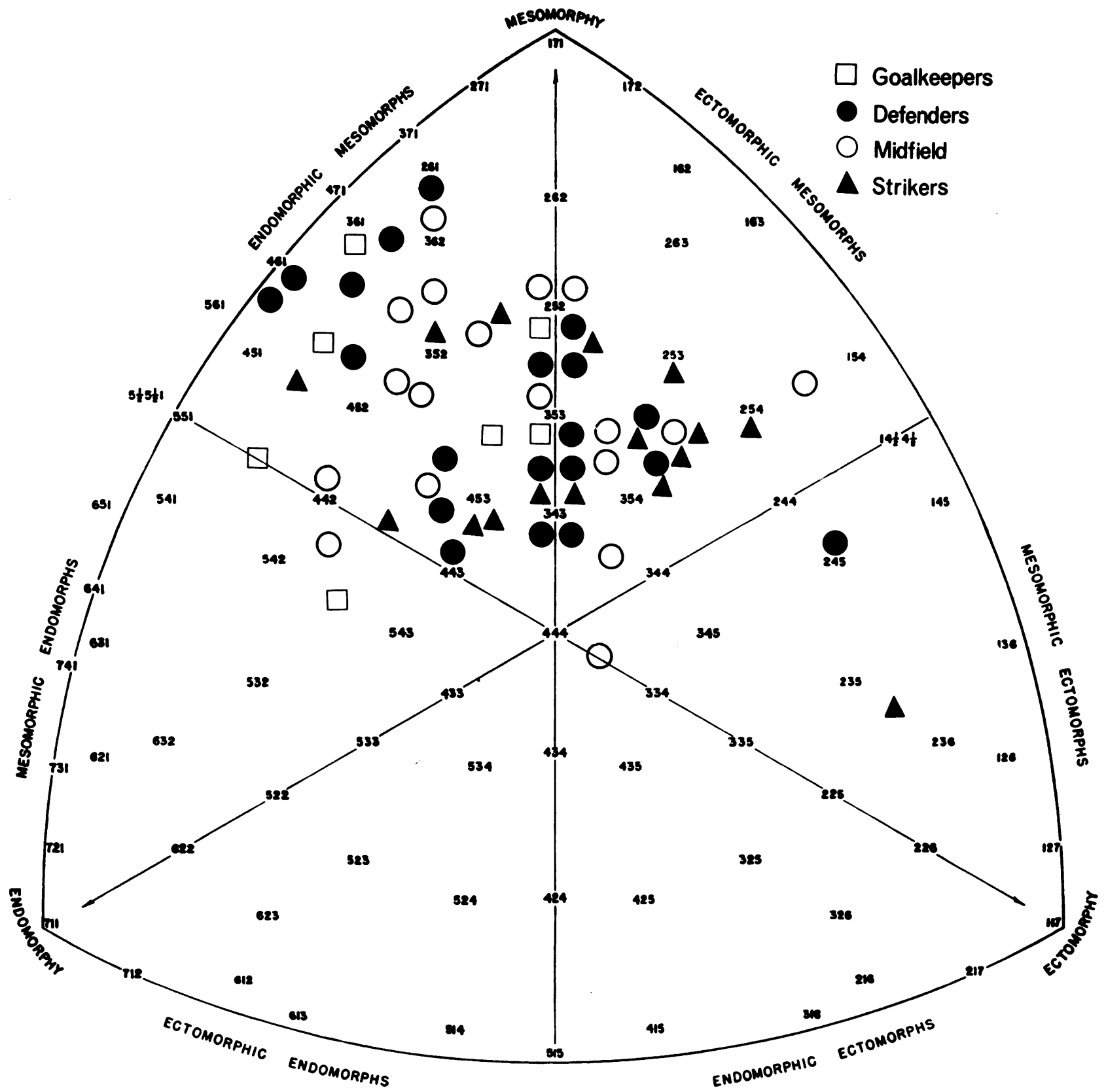

defenders, midfield players, and strikers; defenders with midfield players and strikers; and midfield players with strikers. Chi-square values ranged from 0.79 to 4.58 but did not reach the level for significance ( $p>0.05$ ). Overall, endomorphic mesomorphs accounted for $37 \%$ of the distribution, mesomorphic endomorphs $21 \%$, and balanced mesomorphs $26 \%$. The remaining $16 \%$ were made up from the four other somatotype categories.
Individual somatotypes are illustrated according to playing group in Figure 1.

\section{Discussion}

Stature did not vary a great deal between the playing groups. Goalkeepers were tallest $(180 \mathrm{~cm})$ and midfield players shortest $(173 \mathrm{~cm})$; strikers and defenders fell roughly midway between these two positions $(177 \mathrm{~cm})$. 
This is the kind of arrangement that is usually observed between playing units in game situations.

\section{Table IV}

\begin{abstract}
Mean values and standard deviations of somatotype components according to playing group
\end{abstract}

$\begin{array}{lcccc} & \begin{array}{l}\text { Goalkeeper } \\ (n=7)\end{array} & \begin{array}{c}\text { Defender } \\ (n=20)\end{array} & \begin{array}{c}\text { Midfield } \\ (n=18)\end{array} & \begin{array}{c}\text { Striker } \\ (n=16)\end{array} \\ \text { Endomorphy } & 3.64 & 3.00 & 3.00 & 2.84 \\ & \pm 1.18 & \pm 0.64 & \pm 0.78 & \pm 0.74 \\ \text { Mesomorphy } & 4.92 & 4.92 & 4.86 & 4.59 \\ & \pm 0.73 & \pm 0.79 & \pm 0.65 & \pm 0.58 \\ \text { Ectomorphy } & 2.00 & 2.47 & 2.61 & 3.06 \\ & \pm 0.64 & \pm 1.01 & \pm 0.79 & \pm 0.91\end{array}$

Body mass tended to follow the same kind of pattern as height. The heaviest of all players were goalkeepers

$(81 \mathrm{~kg})$ with midfield players the least heavy $(68 \mathrm{~kg})$. Defenders and strikers fell midway between the two (73 $\mathrm{kg}$ and $69 \mathrm{~kg}$ ). On the basis of mass per unit height goalkeepers were by far. the heaviest followed closely by defenders: differences between midfield players and strikers were slight. Hirata (1966) provided height and weight data for Olympic participants but did not classify players by position so meaningful comparisons between functional groups cannot really be made. The same is true for the data of Medved (1966) and Chovanova and Zrubak (1972). However, the Zagreb data did classify players according to level of performance and showed players of top class ability to be slightly smaller in stature and to have less weight than those of moderate ability. Both these playing groups were found to have smaller values than the population in general.

It has been traditional in soccer to have large defenders, particularly in the central positions; and the same tends to be true for strikers. The difference in height between these two positions was in fact less than a centimetre. Defenders, however, are a trifle larger in the widths of the humerus, femur, and biacromial (Table I) and with their slightly greater body mass would seem to be that bit more robust. As pointed out earlier, none of these differences were significant. Circumferences (Table II) although not showing significant differences between positions provided sume of the largest variance ratios. Apart from goalkeepers having characteristically the largest values, defenders had thigh and calf values about a centimetre larger than strikers, who in turn were greater than midfield men by about half a centimetre. This follows the pattern for height, weight, and in fact most of the other dimensions.

Goalkeepers had more TBF $(17 \%)$ and less LBM (83\%) than other playing units. Subcutaneous tissue values at individual sites (Table II) were also absolutely larger for goalkeepers; other playing positions had similar values at each of the sites. Proportions of TBF (14.7\%) and LBM $(85.3 \%)$ were very similar between defenders, midfield players and strikers. Of the outfield players defenders had the largest absolute amounts but these again were not significant.

There was a distinct difference in arm length between the playing groups, goalkeepers having the longest arms. This of course, like many of the other differences observed, may simply be a reflection of absolute body size, but in any case would be an advantage when playing as goalkeeper. When arm length was expressed in terms of stature all the differences between groups were reduced $(p>0.05)$. Differences were also greater in trunk length than in leg length. Strikers, for example, had the longest legs although not the tallest. To test for differences in trunk and leg length mean differences in leg length between playing positions were adjusted to the same trunk length. The regression equation for leg length on trunk length was $y=0.42 x+42.3$. When this was done the leg length differences did not persist $(p>0.05)$. Similarly, no significant differences existed when biacromial and bi-iliac diameters were compared $(p)$ 0.05).

By and large the somatotypes were confined to the two 'northern' segments of the somatochart. In only one or two instances were individuals outside this region. The mean somatotype of goalkeepers, defenders, and midfield players, would seem to vary around a basic 352 . Goalkeepers, for example, have a half unit extra in endomorphy $\left(3 \frac{1}{2}-5-2\right)$, defenders and midfield players half a unit extra in ectomorphy (3-5-21/2). Strikers appear to be just a little different having a half unit less mesomorphy and a full unit more ectomorphy $\left(3-4 \frac{1}{2}-3\right)$. Variations of individual players from their group means can be seen more clearly from Figure 1.

With one exception goalkeepers were rated $4 \frac{1}{2}$ or above in mesomorphy and $2 \frac{1}{2}$ or below in ectomorphy; the range for endomorphy was greater running from $2 \frac{1}{2}$ to 5. Defenders were all above 4 in mesomorphy, no rating being higher than 6 . Ectomorphic values were between 1 and 3 and endomorphy between 2 and 4 . Of the midfield players only one was below 4 in mesomorphy, most being around 5. Strikers had a consistently homogeneous mesomorphic rating at $4 \frac{1}{2} / 5$. The endomorphic component ranged from 2 to 4 and the ectomorphic one from 2 to 5 .

From the present data it has been shown that goalkeepers were the largest of the playing groups. Defenders and strikers were similar in size, proportion and tissue composition but with defenders being more robust. Dimensions of the midfield player fell roughly midway between those of defenders and strikers. There were no significant differences between the playing units in any 
of the measurements used. The mean somatotype of goalkeepers, defenders and midfield players was a basic 352; strikers were rated at $34 \frac{1}{2} 3$. No significant differences were detected in the somatotypes either.

Since there were no significant differences in any of the variables it would be reasonable for playing groups to be considered as being fairly homogeneous. At this level of ability then there would appear to be no par- ticular somatic characteristics which are especially required for playing in a given position, although clearly there are specific skill and technique requirements. Goalkeepers are perhaps the only group of players which occupy a more specialist role and tend to exhibit dimensions which emphasise this. It would need to be determined, of course, whether or not these considerations are true at other levels of attainment in the game.

\section{REFERENCES}

Bell, W. (1973a). Anthropometry of the young adult rugby player in Wales. Brit.J.Sports Med. 7, 298-299.

Bell, W. (1973b). Distribution of skinfolds and differences in body proportions in young adult rugby players. J.Sports Med.Phys. fitness 13, 69-73.

Carter, J. E. L. (1970). The somatotypes of athletes - a review. Human Biol. 42, 535-570.

Chovanova, E. and Zrubak, A. (1972). Somatotypes of prominent Czechoslovakian Ice Hockey and Football players. Acta F.R.N.Univ Comen.Anthropologia, XXI, 59-63.

Heath, B. H. and Carter, J. E. L. (1967). A modified somatotype method. Amer.J.Phys.Anthropol. 27, 57-74.

Hirata, K. I. (1966). Physique and age of Tokyo Olympic Champions. J.Sports Med.Phys.fitness 6, 207-222.

Medved, R. (1966). Body height and predisposition for certain sports. J.Sports Med.Phys. fitness 6, 89-91.

Tanner, J. M. (1964). The physique of the Olympic Athlete. Allen \& Unwin.

Weiner, J. S. and Lourie, J. A. (1969). Human Biology: a guide to field methods. Blackwell, Oxford. 